\title{
The utilization of infrared imaging for occupational disease study in industrial work
}

\author{
Marcos Leal Brioschi ${ }^{\mathrm{a},}{ }^{*}$, Maria Lúcia Leite Ribeiro Okimoto ${ }^{\mathrm{b}}$ and José Viriato Coelho Vargas ${ }^{\mathrm{c}}$ \\ ${ }^{a}$ Postgraduate Program in Mechanical Engineering, Federal University of Paraná-Curitiba, PR, Brazil \\ ${ }^{\mathrm{b}}$ Deparment of Mechanical Engineering, Federal University of Paraná, Email lucia.demec@ufpr.br,Curitiba, Pr, \\ Brazil, email <lucia.demec@ufpr.br \\ ' Deparment of Mechanical Engineering, Federal University of Paraná, email lucia.demec@ufpr.br,Curitiba, Pr, \\ Brazil, ,Email <vargasjvcv@gmail.com>
}

\begin{abstract}
Infrared imaging has been used to visualize superficial temperatures in industrial employers standing and working in an indoor environment at $22^{\circ} \mathrm{C}$. Temperature distributions and changes have been recorded digitally and analyzed. Mean skin temperatures determined by this method have been compared with superficial temperatures obtained with a probe thermocouple. During working hours, surface temperatures were higher over extensor muscles than over other structures and their spatial distributions differed dramatically from those observed before working hours. The authors also analyzed the cold water immersion of the hands during work. This paper showed that working generates different thermal effects on human skin that reflect physiological and pathological occupational conditions and can be monitored by infrared imaging.
\end{abstract}

Keywords Ergonomics; Infrared image; Occupational disease

\section{Introduction}

According to Jones (1998) the infrared thermal imaging of the skin has been used for several decades to monitor the temperature distribution of human skin in medicine, but more recently the infrared imaging has found an increasing number of applications in engineering and industry. We can cite some studies with specific goals, for example the studies of (Gold et al., 2010; Heus et al.1995, Enander, 1984); that they worked with the skin temperature in the hands of office workers in response to typing. Genno (1997) proposed the procedure to measure the facial skin temperature automatically without physical contact. Piedrahíta et al 2004 consider that the relationship between Musculoskeletal Disorders (MSDs) and cold exposure is limited (Holmér, 1994).

We present this study in order to contribute to the implementation of thermometry in the area of industrial ergonomics. The main purpose of this study was to present a method that can be used to study occupational diseases during work at ambient temperature. The cause of most work-related diseases is not clear and IR imaging can be used to evaluate their physiopathology in loco in order to prevent it.

\section{Methods}

In order to register the human temperature using infrared images, the following methodology was adopted in this study:

Indoors. Experiments were carried out on one day in the month of May on the Federal University of Paraná, in Mechanical Laboratory, which has a red rubber composition surface (Tartan). The track was located indoors with the surroundings maintained at $22.34^{\circ} \mathrm{C}$.

Two workers acted as test subjects (Table 1 gives the physical characteristics of the subjects): one, M.T., has a record of 2 years of active work, and has taken many medical evaluations showing no detecta-

* Corresponding author. E-mail: termometria@yahoo.com.br. Telephone number 0055-41-3362-0623 
ble symptoms; the other, J.B., has a record of 10 years of active work,. Subject M.T. has a work journey of approximately $8 \mathrm{hr}$ every week-day. J.B. works with him on 1 day of the week. The workers were filmed with an infrared camera SAT S-160 (Guangzhou, China) before working hours and at frequent intervals during working hours. The camera was set up at the side of the workstation.

- Surface temperatures during working. The workers stopped at 15 min intervals for tympanic and skin temperature measurements with a thermocouple thermometer. During this time they were filmed with the infrared camera so that probe readings could be compared with the infrared imaging.

- An Ellab Electric Universal Thermometer Type TE3 with a type H1 skin probe was employed. The sensor was made of $0412 \mathrm{~mm}$ michrome and constantan wire stretched between metal supports and having a welded junction. In still air the temperature of exposed skin could be read in 1-2 sec.

- Water hands working experiments. In order to obtain comparable data with cold stress it was necessary to analyze the effect of working with the hands in the water. The temperature of the water was $19.71^{\circ} \mathrm{C}$. The worker put his hands in the cold water for $5 \mathrm{~min}$ before filming again three times. Before working, infrared images were taken, and skin and tympanic temperatures were measured with the probe thermocouple. The following situations were then studied.

- In each situation infrared imaging was taken at intervals until skin temperatures had become constant. Ellab measurements of skin and tympanic temperatures were taken during brief stops at intervals of about $15 \mathrm{~min}$. The total running

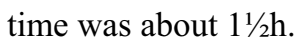

- Thermographic techniques. The SAT S-160 thermovisor consists of an infrared camera coupled to an electronic processor with the thermographic image presented in colour on a monitor screen. A hundred colours are available to represent particular temperatures, and these colours may be arranged in any order. For all of the present experiments the infrared imaging sensitivity was set at $0.1^{\circ} \mathrm{C}$ between adjacent colours, with black being the coolest and white the warmest. It was found that the body surface invariably had a temperature range larger than $10^{\circ} \mathrm{C}$ and greater sensitivity provided large areas of black and white. Additionally, with such an increased sensitivity, the infrared imaging pattern was complicated by having very many small coloured areas making the analyses difficult. The SAT S-160 thermovisor was calibrated by NIST protocols.

- All of the infrared images were recorded on digital format "img" with the camera set up in front of the monitor screen. No measures were taken to eliminate reflections from the surroundings. The scanning rate on the monitor was 16 frames/seconds, and the camera, which was provided with a synchronizer, was run at 8 frames/seconds.

- The infrared digital film showed directly the changing surface temperature patterns. $35 \mathrm{~mm}$ transparencies were made from the $16 \mathrm{~mm}$ film using an Illumitran Copier.

- These transparencies were subsequently projected on a white cardboard screen. Tracings of the images were made and the areas of similar colours cut out and weighed by software. In this way the proportions of total projected areas having similar temperatures on any particular part of the body were determined. By averaging these temperatures and their relative areas, values for mean skin temperatures over various body segments were obtained. 
Table 1

Physical characteristics of subjects

\begin{tabular}{|l|c|c|}
\hline Physical characteristics & Subject 1 (M.T.) & Subject 2 (J.B) \\
\hline Age & 31 & 31 \\
\hline Height $(\mathrm{cm})$ & 179 & 176 \\
\hline Weight $(\mathrm{kg})$ & 65 & 69 \\
\hline Mean skinfold thickness $(\mathrm{mm})$ & 4.18 & 7.1 \\
\hline
\end{tabular}

\section{Results}

Figure 1 shows the thermograms of a man in a standing posture during his work. The face and arms patterns revealed are in accordance with classical descriptions.
The face was warmer and more uniform in temperature than the distal upper limbs. The nose, cheeks, and ears were several degrees cooler than adjacent areas.

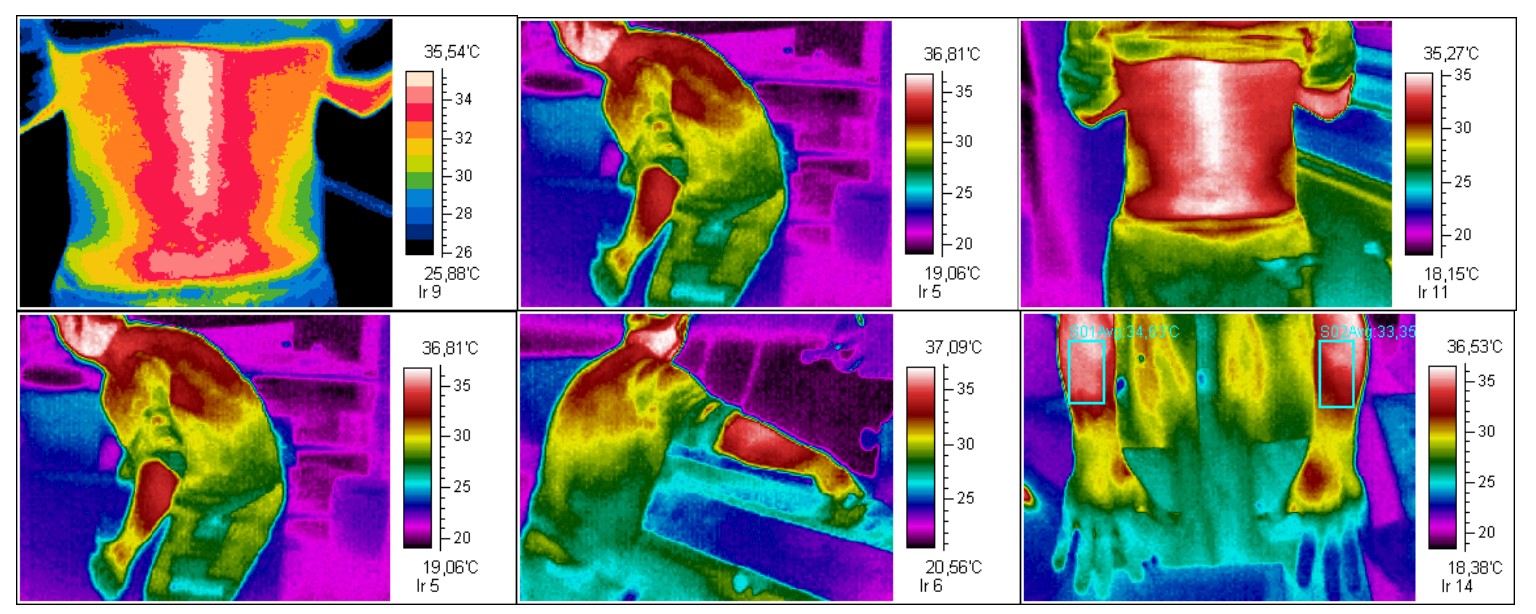

Figure 1- Infrared imaging sequence during working.

The upper limbs showed longitudinal and transverse temperature gradients, creating a pattern reminiscent of, though not identical with the sensory nerve distribution. Skin areas over active muscle, especially at the dominant arm, were $2-4^{\circ} \mathrm{C}$ warmer than over adjacent areas, especially bone.

Infrared digital film showed directly the changing surface temperature patterns during working hours. The arm and back extensor muscles were more warmed during the work, showing a high local muscle activity proportional of his working time.

Infrared digital film showed directly the changing surface temperature patterns during working hours. The arm and back extensor muscles were more warmed during the work, showing a high local muscle activity proportional of his working time.
The workers were not sweating during the infrared filming. Than this was not a monitored variable for the study of the thermograms.

warmed during the work, showing a high local muscle activity proportional of his working time.

It was possible to identify a tunnel carpal syndrome after the cold stress immersion. Although the good thermal response of the fingers after cold stress (fingers at $35.19^{\circ} \mathrm{C}$, delta $\mathrm{T}+10.38^{\circ} \mathrm{C}$ ) there were not adequate at median nerve territory.

The figure 2 to figure 8 shows the sequence of the thermograms of the hands before, during and after cold immersion. The figure 2 shows the thermal map 
of the hand at $27.5^{\circ} \mathrm{C}$ before the work activities. The figure 3 shows the cold immersion of the hands on the water at $19.71^{\circ} \mathrm{C}$. The figure 4 shows Withdrawing iron rings with the Delta $\mathrm{T}$ at $1.99^{\circ} \mathrm{C}$.

In following, putting the cold rings at the rectifier unit is showed by figure 5. It was observed that the temperature of the hand was at $26.88^{\circ} \mathrm{C}$ and the withdrawing the hot iron rings was $38.26^{\circ} \mathrm{C}$. In this time the Delta $\mathrm{T}$ was the $11.38^{\circ} \mathrm{C}$, as shown the figure 6 .

We can see in figure 7 lower temperatures around $24,81^{\circ} \mathrm{C}$ in the blue color of the fingers. And the figure was observed the Hyperemic reaction of the fingers after cold stimulus.

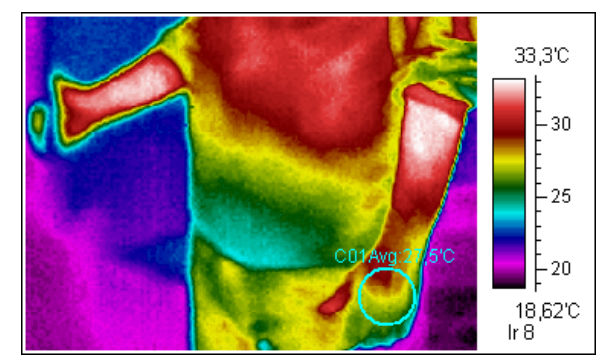

Figure 2. Hand at $27.5^{\circ} \mathrm{C}$ before the work activities

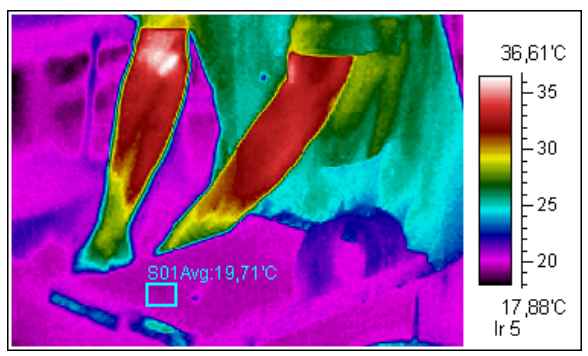

Figure 3. Immersion of the hands on the water.

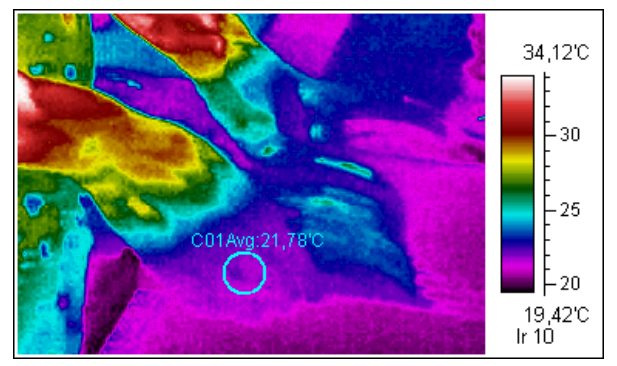

Figure 4. Withdrawing iron rings from the cold water at $19.71^{\circ} \mathrm{C}$. Delta $\mathrm{T} 1.99^{\circ} \mathrm{C}$.

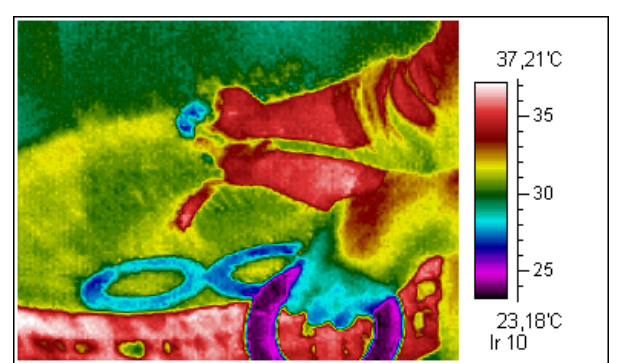

Figure 5. Putting the cold rings at the rectifier unit.

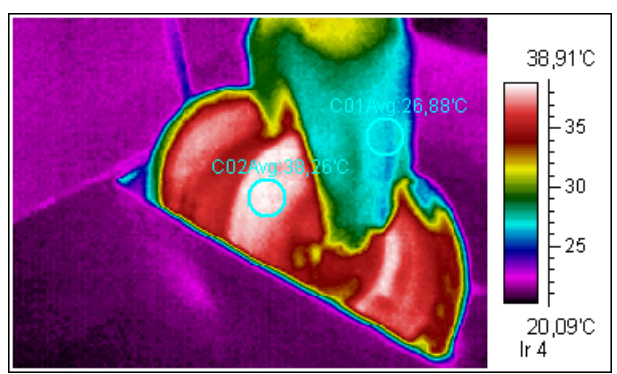

Figure 6 . Cold hand $\left(26.88^{\circ} \mathrm{C}\right)$ withdrawing the hot iron rings $\left(38.26^{\circ} \mathrm{C}\right)$. Delta $\mathrm{T} 11.38^{\circ} \mathrm{C}$.

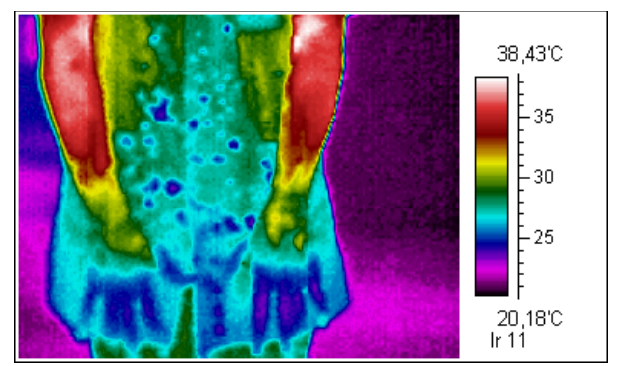

Figure 7. Cold fingers at $24.81^{\circ} \mathrm{C}$

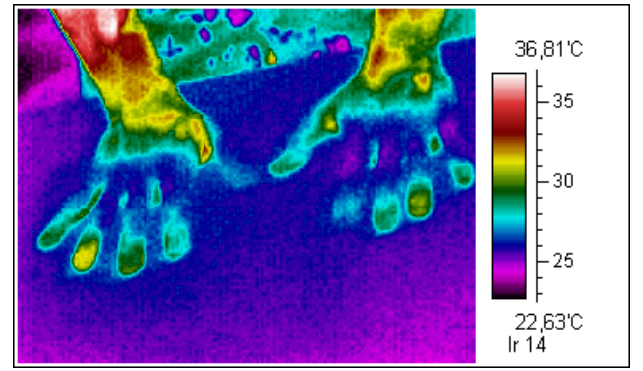

Figure 8. Hyperemic reaction of the fingers. 
It is possible to see after cold immersion the reactive hyperemia phenomena by the high warming of the hands. The Figure 9 shows it graphically comparing the hand and arm temperature during the cold immersion.

By an automatic function, it was possible to observe the maximum temperature point indicating the suspicious areas

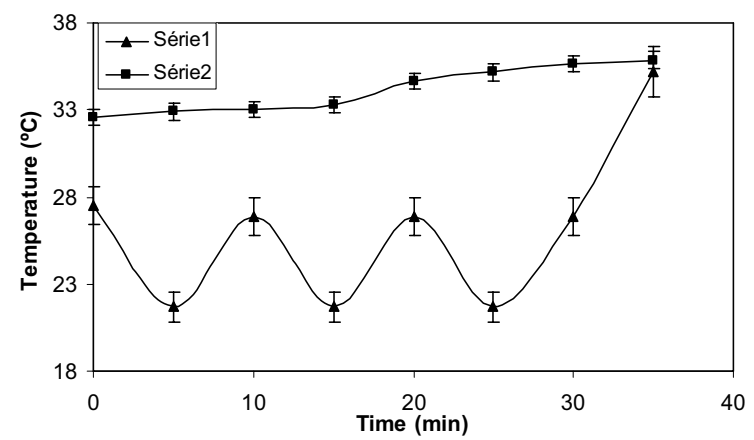

Figure 9. Thermal profile of the hands during and after cold immersion.

\section{Discussion}

This paper showed that working generates different thermal effects on human skin that reflect physiological and pathological occupational conditions.

By infrared imaging was possible to monitor directly the changing surface temperature patterns during working hours. The extensor muscles were more warmed during the work, showing a high local muscle activity proportional of his working time.

Many authors have published papers on the importance of thermography for the study of occupational vasoneurosis (Acciarri et al., 1976; Chucker et al., 1971; Scabardi et al., 1975; Tilila, 1970; Chudacek, 1977). This disease occurs often in patients with a thermal gradient between the carpometacarpal region and the fingers after cold immersion that after this test it is below the initial level. The temperature of the hands is fluctuating (rising and falling), but 45 minutes after cold immersion, the temperature is below the initial level, it is called Raynaud phenomenon.

In our paper we presented a normal worker without symptoms of occupational vasoneurosis. In this subject the temperature of both hands was fast and steadily rising and almost reached the initial level after 5 minutes before being submitted to hands cold immersion again. But after 30 minutes of repetitive immersion it was possible to see the temperature exceeding $7^{\circ} \mathrm{C}$ the initial level. And also identify an asymptomatic median nerve compression thermal pattern at hands, named carpal tunnel syndrome.

People experience cold temperatures as a result of hands immersion in low water temperatures during work (Pienimäki, 2000), from touching cooled or frozen products in cold stores (Piedrahíta et al., 2004). The resulting skin temperatures from cold environments present a health and safety risk in terms of pain and discomfort, numbness, and even skin damage (Daniels, 1956; Chen et al., 1994; Enander, 1986; Havenith et al., 1995). When a person is exposed to cold, there tends to be vasoconstriction in the peripheral musculature (Ducarme and Tikuisis, 1991), as well as in the skin (Berne et al., 2004), due to heat loss. As a result, the blood flow to the extremities is reduced even when the hand is exposed to midly cold temperatures such as $15-25^{\circ} \mathrm{C}$ (Daanen, 1997). The reduction in blood flow may be the cause for losses in tactile sensitivity (Provins and Morton, 1960), reduced manual performance, grip strength (Holewijn and Heus, 1992; Giesbrecht et al., 1995; Geng, 2001, Powell et al., 2000) and increased risk of accidents (Enander, 1984; Havenith et al., 1995; Heus et al., 1995; Geng et al., 2001). Morton and Provins (1960) have found that tactile sensitivity is an L-shaped function of skin temperature and that each individual has a relatively sharp critical temperature at which performance deteriorates significantly. This reduction of sensitivity makes small-object manipulation difficult. Hence, assembly, typing, and small-repair tasks can be adversely affected by cold temperatures if no proper protection is used. Dexterityis decreased when finger temperatures are less than $16^{\circ} \mathrm{C}$ (Clark, 1961; Havenith et al.,1995; Gaydos and Dusek, 1958).

Onset of pain has been reported when the contact temperature is around $15^{\circ} \mathrm{C}(\mathrm{Geng}$ et al., 2006; Malchaire et al., 2002; Havenith et al., 1992, 1995) with a signicant deterioration of tactile discrimination when skin temperatures are less than $8^{\circ} \mathrm{C}$, with numbness inapproximately one-third of the subjects at $7^{\circ} \mathrm{C}$ (Morton and Provins, 1960) and a frostbite threshold at a contact temperature of $0^{\circ} \mathrm{C}$ (Geng et al., 2006). Brajkovic et al.(1998) define the comfortable temperature for fingers to be greater than $23^{\circ} \mathrm{C}$. In this study, we attempted to investigate the thermal pattern of the hands in cold immersion. And we observed that although the employee was working without protection of the hands at cold water, $19^{\circ} \mathrm{C}$, 
he presented a normal vasodilatation reflex of the fingers.

Cold exposure seems to be a causative and contributing factor for tenosynovitis. The risk of carpal tunnel disease in repetitive work increases fivefold when working in a cold environment (Pienimäki, 2000).

Infrared thermography is a mean to study occupational abnormal thermal patterns without interfering with the work.

It is known that skin temperatures are more variable in range and distribution at ambient temperatures between 10 and $20^{\circ} \mathrm{C}$ than they are in a warmer environment (Clark et al., 1977). In this investigation the over-all range of the exposed skin temperature was at $22^{\circ} \mathrm{C}$.

The variation within exposed body regions was generally about $5^{\circ} \mathrm{C}$, although there was as much variation in certain regions, such as the hands as in the head and neck taken together, more than $10^{\circ} \mathrm{C}$.

The higher mean skin temperature over the arms muscles during work are taken to imply that it was dependent on skin surface blood flow for heat loss because of direct heat conduction from the muscles to the skin surface made possible by thinness. This suggests that the total peripheral resistance was maintained and therefore more blood was available for the working muscles.

Skin temperature has the greatest potential for automatic continuous measurement without physical contact, and it is thought to be an effective means for evaluating diseases because autonomic nerve activity associated with vascular, muscle, tendons and nerve disturbances causes skin temperature to vary. Accordingly, the authors looked toward exposed skin temperature of the arms, independently of their movements is easy to measure, in developing a method of evaluating occupational diseases through skin temperature during work.

\section{Conclusion}

The method proposed in the present study enables continuous, non-contact skin temperature measurement at any location of the exposed human body during work at ambient temperature to evaluate occupational disease. This method can be combined with a method that identifies abnormal thermal profiles to prevent disease automatically.
Unfortunately, the system has some limitations because it depends on skin exposition that is not possible in all situations. Therefore, the next step in this line of research will be to evaluate more diseases, adjusting the different individual metabolisms and ambient temperature by a newly proposed dimensionless method.

\section{Acknowledgments}

This research was supported by the Mechanical Engineering Graduate Program at Federal University of Parana (PGMEC), Curitiba, Brazil, and we would like to thank all those who contributed to the success of this research.

\section{References}

[1] A. B. Jones, Reappraisal of the Use of Infrared Thermal Image Analysis in Medicine. IEEE Transactions on Medical Imaging, Vol. 17 (1998), $\mathrm{n}^{\circ} 6$ December

[2] A.Enander, Performance and sensory aspects of work in cold environments: a review. Ergonomics 27 (1984), pp.365-378.

[3] A.Enander, Sensory Reaction and Performance in Moderate Cold. Solna, Sweden. (1986).

[4] D.Brajkovic,. M.B Ducharme,. J. Frim, Influence of localized auxiliary heating on hand comfort during cold exposure. Journal of Applied Physiology 85, (1998).pp. 2054-2065.

[5] E.R. Dusek, Effects of localized hand cooling versus total body cooling on manual performance. Journal of Applied Physiology 12, (1958), 377-380

[6] F.Chen, H. Nilsson, I. Holmer, Cooling responses of finger in contact with an aluminium surface. Journal of American Industrial Hygiene Association 55, (1994), pp. 218-222.

[7] F.Chucker, R. Fowler, T. Motomiya, W. Hurley, Induced temperature transients in Raynaud's disease measured by thermography. Angiology, 22, (1971). 580.

[8] F.Daniels Jr., Contact cooling of the hand at $-20^{\circ} \mathrm{F}$. Technical Report EP-22, US Army, Quartermaster Research and Development Center, Natick, MA. (1956). H.F Gaydos,

[9] G.G.Giesbrecht, M.P.Wu, M.D.White, C.E.Johnston, Bristow, G.K., Isolated effects of peripheral arm and central body cooling on arm performance. Aviation Space and Environmental Medicine 66, (1995).pp. 968-975.

[10] G.Havenith, R.Heus, H.A.Daanen, The hand in the cold, performance and risk. Arctic Medical Research 54 (1995). (Suppl.2), pp.37-47.

[11] G.Havenith, E.J.G.Van de Linde, R.Heus,. Pain, thermal sensation and cooling rates of hands while touching cold materials. European Journal of Applied Physiology 65, (1992), pp.43-51.

[12] H.Genno, A.Saijo, H.Yoshida, R.Suzuki, M.Osumi. Noncontact method for measuring facial skin temperature International Journal of Industrial Ergonomics 19 (1997) 147-159.

[13] H.A.M.Daanen, Vascular reaction to cold: an overview. In central and peripheral control of finger blood flow in the cold. Doctoral Thesis, Vrje Universiteit, Amsterdam, The Netherlands. (1997). 
[14] H.Piedrahíta, L.Punnett, H.Shahnavaz, Musculoskeletal symptoms in cold exponed and non-cold exposed workers. International Journal of Industrial Ergonomics 34(4), (2004), pp. 271-278.

[15] H.Piedrahíta, L.Punnett,.; H.Shahnavaz,. Musculoskeletal symptoms in cold exponed and non-cold exposed workers. International Journal of Industrial Ergonomics 34 (2004) (4), 271-278

[16] J Gold'; M Cherniack,.; A' Hanlon, and ,B Soller. Skin temperature and muscle blood volume changes in the hand after typing. In ternational Journal of Industrial Ergonomics ,Volume 40, Issue 2, March 2010, Pages 161-164.

[17] J.Malchaire, Q.Geng, E.Den Hartog, G.Havenith, I. Holmer, A.Piette, S.L.Powell, H.Rintamaki, S.Rissanen, Temperature limit values for gripping cold surfaces. Annals of Occupational Hygiene 46, (2002). 157-163. K.A.Provins, R.Morton,. Tactile discrimination and skin temperature. Journal of Applied Physiology 15, (1960), pp.155-160.

[18] L.Acciarri, F. Carnevale, A.. Della Selva, Thermography in the hand angiopathy from vibrating tools. Acta Thermographica 1, (1976). pp.18-28. M.B. Ducarme, P. Tikuisis,. In vivo thermal conductivity of the human forearm tissues. Journal of Applied Physiology 70, (1991), pp.2682-2690.

[19] M.Holewijn, R.Heus, Effects of temperature on electromyogram and muscle function. European Journal of Applied Physiology and Occupational Physiology 65, (1992), pp. 541-545.

[20] M.Scabardi, L.Cugola, F.Carnevale, Essai thermographique dans les troubles fonctionelles et organiques de la vascularisation du membre superieur. Quatriéme Séminairz de telethermographie dynamique, Tunis, (1975), 27-30 April.

[21] M Tilila, A preliminary study of the "white finger", using thermographic and other diagnostic tests. Work Environmental Health, 1, (1970). 85
[22] Q.Geng,. Hand cooling, protection and performance in cold environments. National Institute of Working Life (NIWL), Solna, Sweden, Arbete och Hlsa 4, (2001), pp.165.

[23] Q. Geng, I.Holmer, D.E.A.Hartog, G.Havenith, O Jay, J. Malchaire, A.Piette,., H.Rintamaki, S.Rissanen, Temperature limit values for touching cold surfaces with the fingertip. Annals of Occupational Hygiene 50, (2006), pp. 851-862.

[24] R.E.Clark,. The limiting hand skin temperature for unaffected manual performance. Journal of Applied Psychology 45, (1961),pp.193-194.

[25] R.P.Clark, B.J. Mullan, L.G.C.E. Pugh,. Skin temperature during running - a study using infra-red colour thermography. Journal of Physiology, 267, (1977) pp.53-62.

[26] R.Heus, H.A.M Daanen,., G.Havenith,. Physiological criteria for functioning of hands in cold. Applied Ergonomics 26, (1995) 5-13.

[27] R Morton, K.A.Provins, Finger numbness after acute local exposure to cold. Journal of Applied Physiology 15, (1960), pp.149-154.

[28] S.Powell, G.Gavenith, Cold Surface Research Group, The effects of contact cooling on manual dexterity and cooling of the hand. In: Proceedings of the Ninth ICEE Ruhr Conference, Ruhr-University, Bochum, Germany, July 30 August 4, (2000), pp.205-208

[29] T.Pienimäki. Cold exposure and musculoskeletal disorders and diseases. In:Health and Performance in the Cold Workshop, 16-19 May 2000. Policlinic of Occupational Medicine, Oulu Regional Institute of Occupational Health, Oulu, Finland.

[30] Z.Chudacek, Thermography in occupational vasoneurosis. Medical Thermography, Acta Univ Carol Med Monographic, (1977). 